\title{
Períodos de interferência de plantas daninhas na cultura do girassol
}

\author{
Remon Ribeiro da Silva ('); Marcelo Rodrigues dos Reis ('); Kassio Ferreira Mendes $\left({ }^{2 *}\right)$; \\ Leonardo Ângelo de Aquino ('); Dilermando Dourado Pacheco (3); Cláudio Pagotto Ronchi ( ${ }^{1}$ ) \\ (1) Universidade Federal de Viçosa (UFV), Instituto de Ciências Agrárias, 38810-000 Rio Paranaíba (MG), Brasil. \\ (2) Universidade de São Paulo (USP), Centro de Energia Nuclear na Agricultura, 13400-970 Piracicaba (SP), Brasil. \\ (3) Instituto Federal do Norte de Minas Gerais (IFNMG), Departamento de Agronomia, 39480-000 Januária (MG), Brasil. \\ (*) Autor correspondente: kassio_mendes_06@hotmail.com
}

Recebido: 16/jul./2013; Aceito: 5/set./2013

\begin{abstract}
Resumo
Objetivou-se neste trabalho determinar os períodos de interferência de plantas daninhas na cultura do girassol. Foram realizados dois experimentos com o girassol híbrido Helio 250, sendo um conduzido no verão e o outro, no inverno. Para ambos, o delineamento experimental utilizado foi em blocos casualizados, com quatro repetições, e cada unidade experimental foi constituída de cinco linhas de plantas com 6,0 m de comprimento, espaçadas por 0,7 m. No experimento de verão foram avaliados oito períodos de convivência e controle de plantas daninhas: 10, 20, 30, 40, 50, 60, 70 e 88 dias após a emergência (dae). No experimento de inverno, os períodos foram: 7, 14, 21, 28, 38, 48, 58 e 82 dae. Avaliaram-se a massa da matéria seca e a área foliar das plantas de girassol, produtividade, massa de mil aquênios e massa da matéria seca de plantas daninhas. Estimaram-se os períodos anteriores à interferência (PAI), períodos críticos de prevenção à interferência (PCPI) e períodos totais de prevenção à interferência (PTPI). Considerando-se a produtividade de aquênios no verão, o PAl foi de 16 dae da cultura, o PTPI, de 39 dae e o PCPI abrangeu 23 dias do ciclo da cultura. No inverno, o PAl foi de 12 dae, o PTPI estendeu-se até os 34 dae, resultando em um PCPI de 22 dias.
\end{abstract}

Palavras-chave: Helianthus annuus L., competição, produtividade.

\section{Interference periods of weeds in sunflower crop}

\begin{abstract}
The objective of this work was to determine the periods of weed interference in sunflower crops. Two experiments were done with the sunflower hybrid Helio 250, one in the summer and the other in the winter. For both experiments, a randomized block design with four repetitions was used and each experimental unit was composed of plants in five lines, $6.0 \mathrm{~m}$ in length, spaced $0.7 \mathrm{~m}$ apart. In the summer experiment eight periods of cohabitation and weedy plant control were evaluated: 10, 20, 30, 40, 50, 60, 70 and 88 days after emergence (dae). In the winter experiment, the periods were 7, 14, 21, 28, 38, 48, 58 and 82 dae. The dry matter mass, leaf area of sunflower plants, yield, thousand achenes mass and weedy plant dry matter mass were evaluated. The periods prior to interference (PPI), the critical periods of preventing interference (CPPI), and the total periods of preventing interference (TPPI) were estimated. Considering the yield of achenes in the summer, the PPI was 16 dae of the crop, the CPPI was 39 dae and the TPPI lasted 23 days of the crop cycle. In winter, the PPI was 12 dae and the CPPI lasted for 34 dae, resulting in a TPPI of 22 days.
\end{abstract}

Key words: Helianthus annuus L., competition, yield.

\section{INTRODUÇÃO}

O girassol (Helianthus annuus L.) é uma magnoliopsida (dicotiledônea) anual da família Asteraceae originária do continente norte-americano mas que é cultivada em todos os continentes, destaca-se mundialmente como importante cultura oleaginosa e apresenta ciclo curto e alta produção de óleo (Porto et al., 2007; SiLVA et al., 2007; THOMAz et al., 2012). Essa cultura tem crescimento inicial lento. A partir de 30 dias após a emergência, o crescimento se torna acelerado, o que permite eficiente competição do girassol com as plantas daninhas (BRIGHENTI et al., 2004). Dessa forma, nos estádios mais avançados, a cultura pode ser considerada boa competidora, mas sua época de semeadura muitas vezes coincide com o verão, quando há um maior crescimento e competitividade das plantas daninhas, que tornam-se um problema para a cultura (Montoya et al., 2007).

O manejo de plantas daninhas é uma das principais práticas adotadas no sistema de produção do girassol. A interferência dessas plantas pode resultar em perda de produtividade, menor qualidade do produto colhido 
ou aumento do custo de produção da cultura. A base para a formulação de uma proposta de controle eficiente é o conhecimento da flora daninha que ocorre nas áreas de cultivo (ADEgas et al., 2010).

Nesse sentido, o conhecimento dos períodos de interferência na cultura do girassol é útil para o desenvolvimento de melhores estratégias de manejo de plantas daninhas, indicando o intervalo de tempo ideal para seu controle em determinados sistemas de cultivo e localidades. Pitelli (1985) designou três períodos de interferência: período anterior à interferência $(\mathrm{PAI})$, período total de prevenção à interferência (PTPI) e período crítico de prevenção à interferência (PCPI).

PAI é o período a partir da semeadura ou do plantio de determinada cultura em que ela pode conviver com a comunidade infestante sem que a produtividade seja reduzida. No PTPI, a cultura deve ser mantida livre de plantas daninhas; as plantas daninhas que vierem a infestar a área após esse período não causam danos significativos à cultura. O PCPI é representado pelo intervalo entre os dois períodos mencionados e durante ele é indispensável à realização do controle das plantas daninhas (PitelLi, 1987; SwANTON et al., 2008).

O controle das plantas daninhas na cultura do girassol até 15 a 20 dias após a emergência (dae), por um período de 40 a 45 dias, proporciona incrementos nos componentes de produção da cultura (FLECK et al., 1989). No entanto, pesquisas evidenciam grande variabilidade nos períodos para a cultura do girassol. Tal fato reforça a ideia que há necessidade de repetir esses trabalhos em diversas condiçóes, para que se garanta base de dados confiáveis sobre os efeitos da interferência de plantas daninhas (BRIGHENTI et al., 2004; KneZevic et al., 2002; SiLva et al., 2012).

Nos EUA, o efeito da interferência de plantas daninhas na cultura do girassol apresentou PCPI entre quatro e seis semanas (Johnson, 1971). Para a produtividade de aquênios do híbrido de girassol M 734, o PAI foi de 15 dae e o PTPI foi de 39 dae (SiLva et al., 2012). Por outro lado, o PCPI foi de 20 a 49 dias após a semeadura do girassol, apresentando perda máxima de $54,6 \%$ na produtividade quando em convivência com as plantas daninhas (WaNJari et al., 2001).

Estudos relataram que o intervalo de tempo de permanência das plantas daninhas na cultura do girassol, sem aplicação de herbicida pré-emergente, variou de 14 a 26 dae, o que correspondeu à transição do estádio fenológico V3 (três folhas) para as fases de crescimento V4, com base no nível de $5 \%$ de perdas de produtividade aceitáveis (Elezovic et al., 2012).

Diante do exposto, objetivou-se com este trabalho determinar os períodos de interferência de plantas daninhas na cultura do girassol híbrido Helio 250 em duas épocas de cultivo na região do norte de Minas Gerais.

\section{MATERIAL E MÉTODOS}

Os experimentos foram realizados no município de Januária,

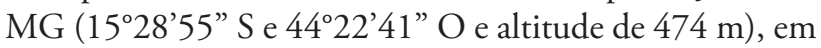
solo classificado como Neossolo Quartzarênico órtico típico (EMBrapa, 2006). O solo apresentou granulometria de 87,0; 3,0 e 10,0 dag kg-1 de areia, silte e argila, respectivamente, em ambos os experimentos, na profundidade de $0-20 \mathrm{~cm}$. Para a época de verão: $\mathrm{pH}\left(\mathrm{H}_{2} \mathrm{O}\right)=5,4 ; \mathrm{P}=74,1 \mathrm{mg} \mathrm{dm}^{-3}$; M.O. $=6,0 \mathrm{dag} \mathrm{kg}^{-1} ; \mathrm{K}=82,0 \mathrm{mg} \mathrm{dm}^{-3} ; \mathrm{Ca}=2,0 \mathrm{cmol}_{\mathrm{c}} \mathrm{dm}^{-3}$; $\mathrm{Mg}=0,5 \mathrm{cmol}_{\mathrm{c}} \mathrm{dm}^{-3} ; \mathrm{H}+\mathrm{Al}=1,2 \mathrm{cmol}_{\mathrm{c}} \mathrm{dm}^{-3}$; $\mathrm{SB}=2,7 \mathrm{cmol} \mathrm{dm}_{\mathrm{c}}^{-3}$; CTC $=2,7 \mathrm{cmol}_{\mathrm{c}} \mathrm{dm}^{-3} \mathrm{e} \mathrm{V}=70,0 \%$. Para a época de inverno: $\mathrm{pH}\left(\mathrm{H}_{2} \mathrm{O}\right)=6,6 ; \mathrm{P}=65,0 \mathrm{mg} \mathrm{dm}^{-3}$; M.O. $=0,6 \mathrm{dag} \mathrm{kg}^{-1} ; \mathrm{K}=36,0 \mathrm{mg} \mathrm{dm}^{-3} ; \mathrm{Ca}=1,9 \mathrm{cmol}_{\mathrm{c}} \mathrm{dm}^{-3}$; $\mathrm{Mg}=0,4 \mathrm{cmol}_{\mathrm{c}} \mathrm{dm}^{-3} ; \mathrm{H}+\mathrm{Al}=1,0 \mathrm{cmol}_{\mathrm{c}} \mathrm{dm}^{-3}$; $\mathrm{SB}=2,4 \mathrm{cmol}_{c} \mathrm{dm}^{-3}$; CTC $=2,4 \mathrm{cmol} \mathrm{dm}_{c}^{-3}$ e V=70,0\%.

O clima predominante da região é do tipo Aw, tropical úmido com inverno seco e verão chuvoso, segundo a classificação internacional de Köppen (Sousa et al., 2011). Durante a realizaçáo do experimento, o veráo apresentou precipitação acumulada de $512,4 \mathrm{~mm}$, com temperatura média variando entre $25,4^{\circ} \mathrm{C}$ e $26,6^{\circ} \mathrm{C}$. O inverno apresentou precipitação acumulada de $41,5 \mathrm{~mm}$, com temperatura média variando entre $21,1^{\circ} \mathrm{C}$ e $28,5^{\circ} \mathrm{C}$.

Foram conduzidos dois experimentos entre janeiro de 2009 e outubro de 2010; a semeadura do primeiro experimento foi realizada dia 13 de janeiro de 2009 e a do segundo, em 23 de julho de 2010.

O experimento instalado em 2009 foi submetido a oito períodos crescentes de controle ou convivência de plantas daninhas $(10,20,30,40,50,60,70$ e 88 dias após a emergência - dae). No experimento de 2010 , os períodos foram: $7,14,21,28,38,48,58$ e 82 dae. No período de controle, a cultura foi mantida no limpo, sendo que a plantas daninhas que emergiram após esses intervalos não foram mais controladas. O controle foi realizado por meio de capinas manuais nas entrelinhas e amontoa nas proximidades da linha de semeadura.

Para ambos os experimentos, o delineamento experimental utilizado foi em blocos casualizados, com quatro repetiçôes. Cada unidade experimental foi constituída de cinco linhas de semeadura com $6 \mathrm{~m}$ de comprimento, espaçadas entre si por $0,7 \mathrm{~m}$.

O solo foi previamente preparado por meio de uma aração e gradagem. A semeadura foi realizada manualmente, colocando-se três sementes, espaçadas em $0,33 \mathrm{~m}$, na linha. Logo após a emergência foi realizado um desbaste, permanecendo três plantas por metro. O híbrido de girassol utilizado em todas as épocas de cultivo foi o híbrido Helio 250 (híbrido simples, com porcentagem de óleo entre $44 \%$ e $48 \%$, altura média das plantas entre 160 e $180 \mathrm{~cm}$ e maturação fisiológica entre 85 e 105 dias).

A adubação de plantio consistiu-se de $250 \mathrm{~kg} \mathrm{ha}^{-1}$ da fórmula NPK 04-30-10. Na adubaçâo de cobertura foram 
utilizados $100 \mathrm{~kg} \mathrm{ha}^{-1}$ de $\mathrm{N}$ e $75 \mathrm{~kg} \mathrm{ha}^{-1}$ de $\mathrm{K}_{2} \mathrm{O}$, na forma de ureia e cloreto de potássio, respectivamente; parcelados em duas aplicaçôes: nos estádios fenológicos $V_{3}$ e $V_{6}$ da cultura. Realizaram-se irrigaçóes diárias, visando atingir a capacidade de campo do solo. A lâmina aplicada variou de acordo com a evapotranspiração estimada pela estação meteorológica instalada próxima ao experimento.

Para o controle de pragas no primeiro cultivo, especialmente da lagarta-do-girassol (Chlosyne lacinia saundersi), foi realizada aplicação com pulverizador costal pressurizado por $\mathrm{CO}_{2}$ dos inseticidas deltamethrin e triazofós na dosagem 0,5 e $175 \mathrm{~g} \mathrm{ha}^{-1}$, respectivamente.

A área foliar e a massa da matéria seca das plantas de girassol foram determinadas a partir da coleta de quatro plantas por parcela no estádio fenológico $\mathrm{R}_{1}$. Nesse estádio, $50 \%$ das plantas estão no início da emissão do botáo floral, segundo Castiglioni et al. (1997). A área foliar foi obtida através da projeção dos limbos foliares em papel milimetrado. As áreas projetadas no papel foram calculadas pela interpolação entre massas de área conhecida do papel e a massa dos limbos foliares coletados.

Para obtenção da massa da matéria seca da planta, suas partes constituintes: caule, pecíolo, limbos foliares e capítulo foram secas em estufa com circulação de ar forçado a $70^{\circ} \mathrm{C}$ por um período de $72 \mathrm{~h}$, até atingir-se massa constante. A quantificação da massa da matéria seca das plantas daninhas, coletadas logo após os períodos de convivência e ao final do experimento, foi realizada em área de $0,25 \mathrm{~m}^{2}$ de cada unidade experimental e os valores extrapolados em matéria seca por $\mathrm{m}^{2}$. O material foi levado para estufa e secado conforme citado anteriormente. Em cada unidade amostrada, as plantas foram identificadas segundo a espécie.

No cultivo de verão, as espécies de plantas daninhas que ocorreram foram: Acanthospermum hispidum, Cenchrus echinatus, Cyperus rotundus, Ipomoea spp. e Portulaca oleracea. No cultivo de inverno, as plantas daninhas na área experimental foram: Acanthospermum hispidum, Amaranthus spp., Cenchrus echinatus, Galinsoga parviflora, Ipomoea sp. e Portulaca oleracea. Não foram registradas a densidade geral ou específica, apenas a ocorrência das espécies de plantas daninhas.

$\mathrm{Na}$ colheita foram estimadas a massa de mil aquênios e a produtividade do girassol, sendo colhidas manualmente as três linhas centrais de cada parcela. A massa de mil aquênios foi estimada em amostra de $200 \mathrm{~g}$ retirada aleatoriamente de cada unidade experimental. Essa amostra foi utilizada na determinação do teor de umidade, para correção da produtividade a $13 \%$ de umidade.

Para determinação do período crítico de prevenção à interferência (PCPI), foi utilizado o modelo logístico, sendo a produtividade o parâmetro de determinação. Esse modelo é expresso pela equação logística (1):

$\mathrm{y}=\mathrm{y}_{0}+\mathrm{a} /\left(1+\left(\mathrm{x} / \mathrm{x}_{0}\right)^{\mathrm{b}}\right.$ em que $\mathrm{y}=$ produtividade máxima da cultura; $\mathrm{y}_{0}=$ produtiidade mínima encontrada nas parcelas onde a cultura conviveu com a planta daninha durante todo o período; $a=$ diferença entre as produtividades máxima e mínima nas parcelas mantidas limpas durante todo o período; $\mathrm{x}=$ dias após a emergência do girassol; $\mathrm{x}_{0}=$ número de dias em que ocorreu $50 \%$ de redução na produtividade máxima; e b=declividade da curva.

A produtividade obtida nos períodos de controle e de convivência foram ajustados com modelo de regressão não linear pelo teste de $\mathrm{F}(\mathrm{p}<0,01$ e 0,05$)$, através do software SigmaPlot 11.0. O PCPI foi estimado com base em redução de $5 \%$ da produtividade máxima estimada pelo modelo logístico, considerando-se que esse valor refere-se ao custo do controle químico das plantas daninhas.

\section{RESULTADOS E DISCUSSÃO}

A massa da matéria seca das plantas daninhas nos períodos de convivência com a cultura no verão apresentou incremento máximo de $190 \mathrm{~g} \mathrm{~m}^{-2}$ aos 70 dae (Figura 1a). Entretanto, no final do experimento, aos 88 dae houve uma redução de $9 \%$ na massa da matéria seca. E no inverno apresentou incremento até 65 dae, com valor máximo de $176 \mathrm{~g} \mathrm{~m}^{-2}$, porém na última avaliaçáo a massa da matéria seca decresceu em $10 \%$. Tal fato pode ser justificado pelo aumento da competição inter e intraespecífica estabelecida pela comunidade de plantas daninhas, havendo um maior requerimento de recursos do meio (BRIGHENTI et al., 2004) e também pela senescência das plantas, em virtude do término de seu ciclo de vida.

De acordo com Pitelli (1987), as plantas daninhas geralmente crescem em comunidades densas, sendo assim, o crescimento é variável conforme a disponibilidade de recursos passíveis de serem mobilizados e não de acordo com seu potencial genético. Desse modo, o potencial de crescimento da comunidade é controlado pelo recurso mais escasso.

Para o girassol cultivado no veráo, nos tratamentos de controle das plantas daninhas por períodos crescentes, observou-se rápido incremento da massa da matéria seca de plantas daninhas dos 10 aos 40 dae. O aumento da massa da matéria seca das plantas daninhas nesse período reduziu a massa da matéria seca do girassol em 40\% (Figura 2a). Quando observados os períodos nos quais a cultura conviveu com as plantas daninhas, verificou-se diminuição da massa da matéria seca das plantas de girassol da ordem de $13 \%$ entre 20 e 50 dae. Esse valor representa um decréscimo de aproximadamente $1,2 \mathrm{tha}^{-1}$ de massa da matéria seca da cultura.

No inverno, a massa da matéria seca do girassol reduziu-se do $7^{\circ}$ ao $38^{\circ}$ dae quando em convivência com plantas daninhas, decrescendo $10 \%$. No entanto, verificou-se um incremento da massa da matéria seca até $60^{\circ}$ dae, mesmo com o aumento da duraçáo dos períodos de convivência 

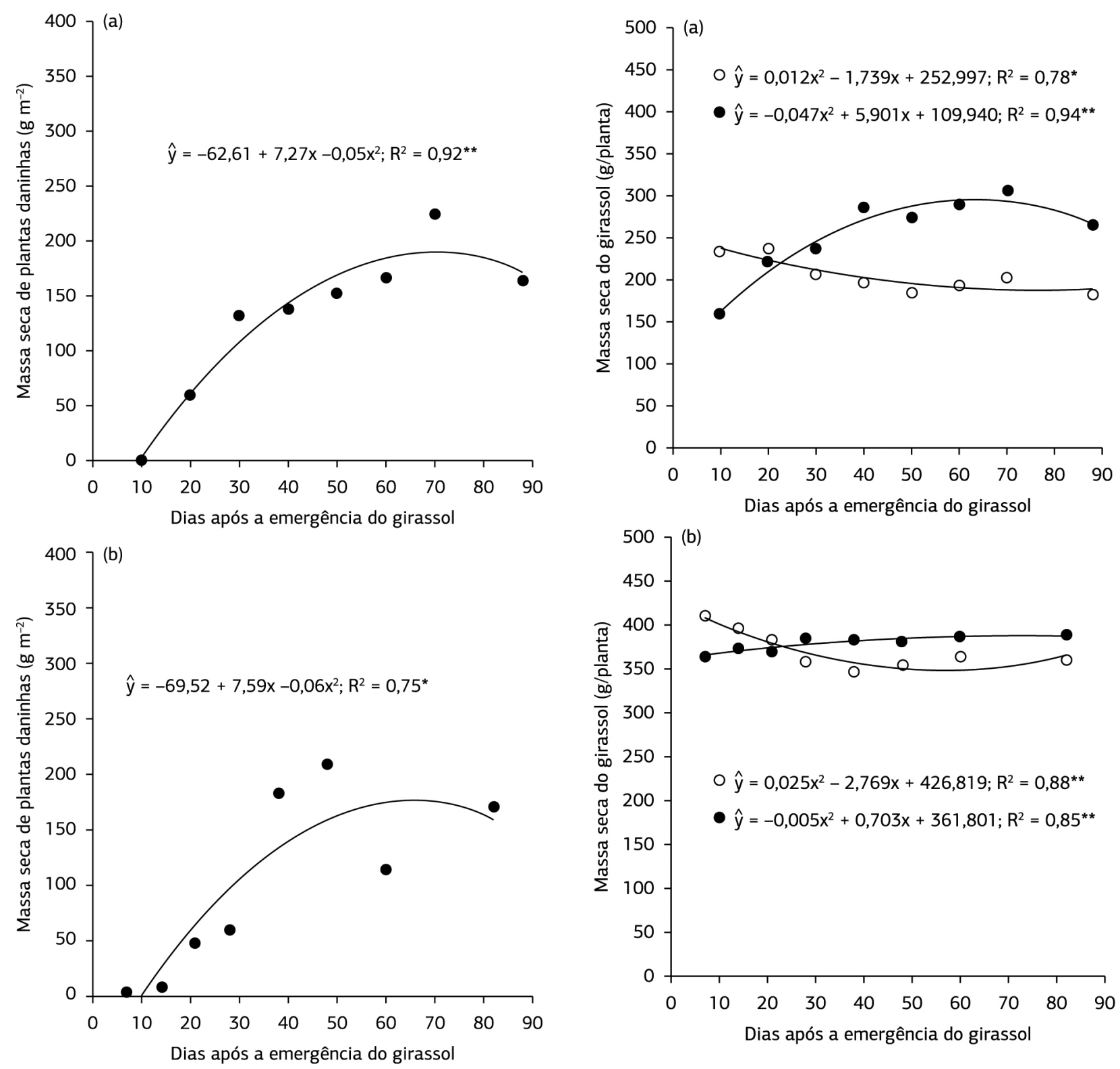

Figura 1. Massa da matéria seca de plantas daninhas nos períodos de convivência com a cultura do girassol Helio 250 no verão (a) e n o inverno (b), em Januária, MG. ${ }^{* *} \mathrm{e}^{*} \mathrm{p}<0,01$ e 0,05 pelo teste de $\mathrm{F}$.

Figura 2. Massa da matéria seca da parte aérea de plantas de girassol Helio 250 no estádio R1 cultivadas no verão (a) e no inverno (b), em funçáo dos períodos com (o) e sem $(\bullet)$ convivência com plantas daninhas, em Januária, MG. ${ }^{* *} \mathrm{e}^{*} \mathrm{p}<0,01$ e 0,05 pelo teste de F.

(Figura 2b). Esse comportamento pode ter sido influenciado pelo aumento da temperatura verificado a partir do mês de agosto (de $21,1^{\circ} \mathrm{C}$ para $28,5^{\circ} \mathrm{C}$ ). $\mathrm{O}$ mesmo comportamento foi verificado nos períodos sem interferência das plantas daninhas, notando-se um aumento mais pronunciado entre 28 e 38 dae em função da menor competição. Corroborando os dados, foi observado que a taxa de crescimento do girassol está associada positivamente com a temperatura (BARNi et al., 1995).

No cultivo de verão (Figura $2 \mathrm{a}$ ) e no de inverno (Figura $2 \mathrm{~b}$ ), sem convivência com as plantas daninhas, notou-se uma tendência de redução e de estabilização na massa da matéria seca do girassol, respectivamente, no

final do ciclo, a partir dos 80 dae. Isso pode ser atribuído à senescência da cultura.

Em ambos os cultivos observou-se rápido incremento da área foliar do girassol, após os 28 e 30 dae nas parcelas sem convivência do cultivo de veráo e inverno, respectivamente (Figura 3a,b). O crescimento do girassol é lento até os 30 dae e após esse período é acelerado, com aumento acentuado da área foliar, segundo Silva et al. (2012).

De forma similar para a massa da matéria seca, o aumento $\mathrm{da}$ área foliar no cultivo de inverno pode ter se dado pela elevação da temperatura no mês de agosto. A expansão da área foliar do girassol foi mais rápida em temperaturas mais elevadas e retardou-se sob temperaturas menores; dessa forma, 

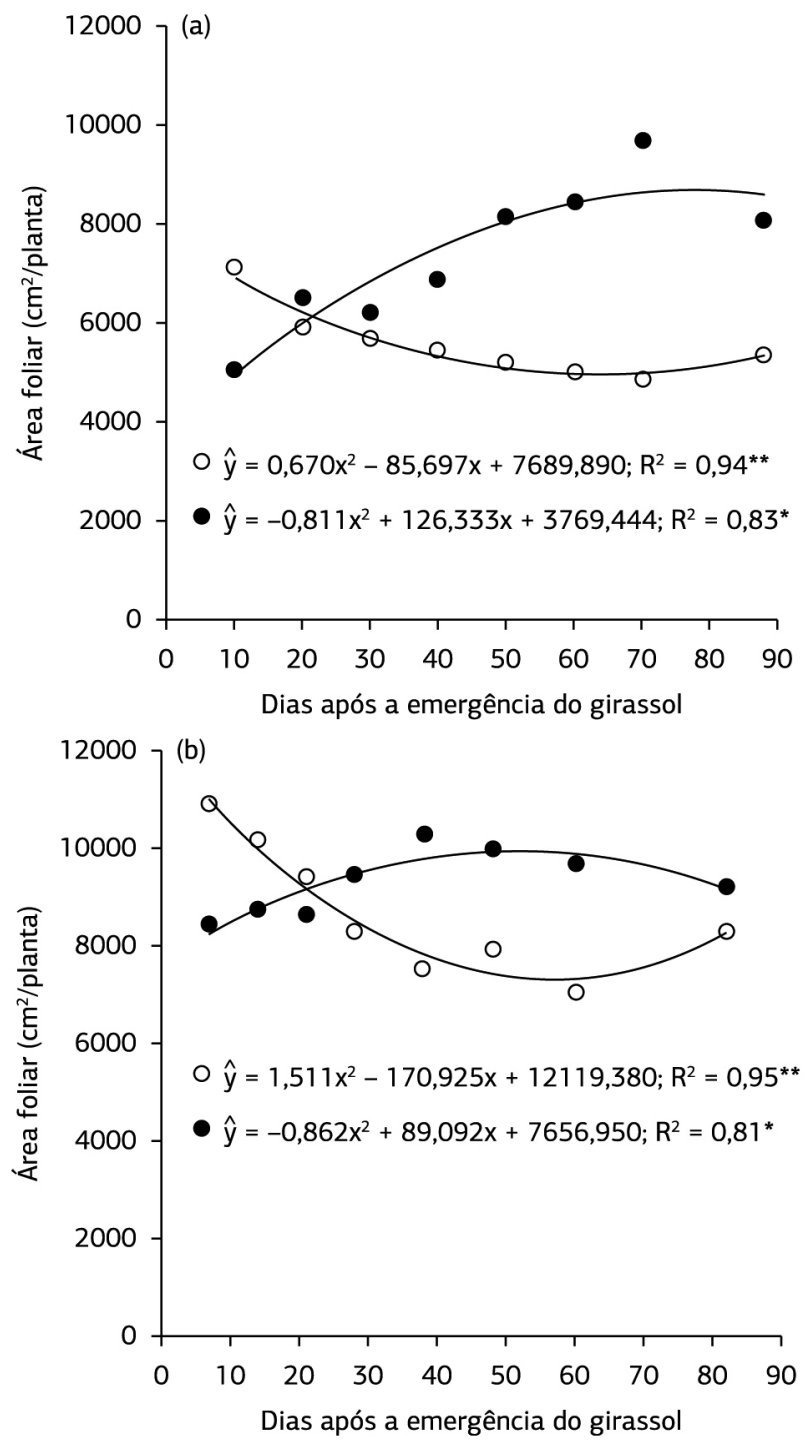

Figura 3. Área foliar do girassol Helio 250 no estádio R1 cultivado no veráo (a) e no inverno (b), em função dos períodos com (o) e sem $(\bullet)$ convivência com plantas daninhas, em Januária, MG. ${ }^{* *} \mathrm{e}^{*}$ $\mathrm{p}<0,01$ e 0,05 pelo teste de $\mathrm{F}$.

a taxa de expansão da foliar é influenciada pela temperatura (Andrade e Abreu, 2007).

Houve expressiva reduçáo da área foliar do girassol quando ele conviveu por 14 e 20 dae com plantas daninhas, nos cultivos de verão e inverno, respectivamente (Figura 3a,b). Provavelmente, o crescimento lento das plantas de girassol, associado ao aumento da massa da matéria seca das plantas daninhas, evidencia uma maior interferência nesse período.

Constatou-se que a massa de mil aquênios média submetida a todos os períodos de convivência ou controle de plantas daninhas no girassol foi de 48,9 e 64,9 g, no verão e no inverno, respectivamente. Observou-se que os períodos com convivência ou controle de plantas daninhas não afetaram essa variável.

A produtividade de aquênios do girassol é definida pelo produto do número de capítulos por unidade de área, o número de aquênios de cada capítulo e a massa dos aquênios (Silva et al., 1995). A convivência de plantas daninhas não afetou a massa de mil aquênios mas interferiu diretamente na produtividade (FLECK e VIDAL, 1993). Os autores relatam que houve uma correlação linear positiva entre número de aquênios por capítulo e a produtividade, mas a correlação entre massa de mil aquênios e produtividade não apresentou significância. Logo, concluíram que a diferença na produtividade está associada a variaçôes ocorridas no número de aquênios por capítulo.

Os períodos de convivência não causaram efeito na quantidade de capítulos por área, mas os autores relataram redução significativa no número de aquênios por capítulo sob períodos crescentes de convivência com plantas daninhas em diferentes locais e épocas (Elezovic et al., 2012). No entanto, em seu estudo, verificaram redução na massa de mil aquênios, fato não observado neste trabalho.

A convivência entre o girassol e as plantas daninhas além de 16 dae reduziu a produtividade do girassol cultivado no verão (Figura 4a). Dessa forma, nessa época de cultivo, o PAI foi de até 16 dae. $O$ período total de prevenção à interferência (PTPI) foi de 39 dae, pois o controle de plantas daninhas após esse período não incrementou a produtividade de aquênios. Com isso, o período crítico de prevenção à interferência (PCPI) se caracterizou pelo intervalo entre 16 e 39 dae, totalizando 23 dias. Durante esse período, a cultura deve ser mantida livre da interferência de plantas daninhas. A convivência com plantas daninhas durante todo o ciclo exerceu forte interferência sobre a produtividade do girassol, causando reduçáo de $36 \%$ na produtividade de aquênios no cultivo de verão.

A opção pelo uso da equação logística deve-se ao fato de todos os seus componentes terem um significado biológico, permitindo a determinação do PCPI (KozLowsKI, 2002). Assim, vários estudos determinam o PCPI na cultura do girassol considerando como base um nível de 5\% de perda aceitável na produtividade de aquênios (Alves et al., 2013; Brighenti et al., 2004; Elezovic et al., 2012; Silva et al., 2012).

Os dados corroboram os de Silva et al. (2012), que trabalharam com o cultivar M 734 considerando perdas de $5 \%$ na produtividade de aquênios e constataram que o PCPI compreendeu de 15 a 39 dae. Entretanto, os autores verificaram que a convivência do girassol com plantas daninhas durante todo o ciclo reduziu a produtividade da cultura em 19\%. A convivência das plantas daninhas durante todo o ciclo do girassol cultivar Embrapa 122/V 2000 reduziu em 33,06\% a produtividade de grãos da cultura (FurTado et al., 2012).

Estudos realizados no Canadá relatam que a produtividade do girassol não foi afetada quando as plantas de aveia selvagem (Avena fatua) foram removidas até 28 dae (Chubb e Friesen, 1985). Os dados corroboram os de BRIGHENTI et al. (2004), que verificaram que a convivência do girassol com plantas daninhas até os 30 dae ocasionou perdas diárias na produção 

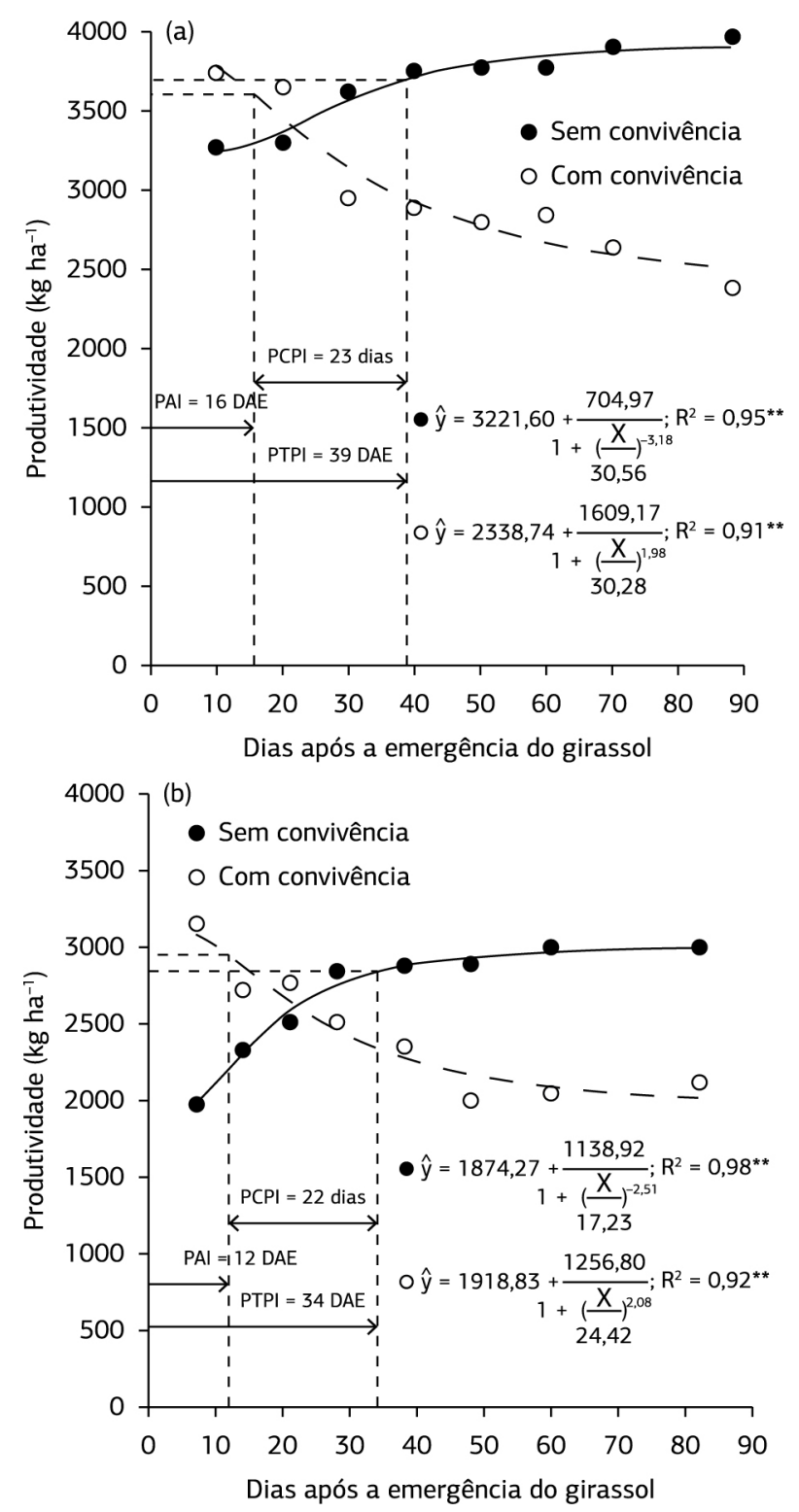

Figura 4. Produtividade de aquênios de girassol Helio 250 cultivado no verão (a) e no inverno (b), em função dos períodos com e sem convivência com plantas daninhas, em Januária, MG. ${ }^{* *} \mathrm{e}^{*} \mathrm{p}<0,01$ e 0,05 pelo teste de $F$.

de óleo e na produtividade da cultura da ordem de $1,1 \mathrm{e}$ $2,5 \mathrm{~kg} \mathrm{ha}^{-1}$, respectivamente. De outra forma, no mesmo período e mantida livre de plantas daninhas, a cultura apresentou incremento médio diário de 6,5 e 14,4 $\mathrm{kg} \mathrm{ha}^{-1}$ nos mesmos componentes de produção, respectivamente. Neste estudo, os autores verificaram que o PCPI situou-se entre 21 e 30 dae.

Observou-se no PCPI que a massa da matéria seca apresentou aumento até os 40 dae (Figura 2a). É possível que a cultura tenha estabelecido maior capacidade de sombreamento do solo, tornando-se mais competitiva e originando o PTPI de 39 dae. Pitelli (1987) ressalta que, após o PTPI, o sombreamento é uma das principais formas de controle e impedimento do crescimento de plantas daninhas.
Evidencia-se que as plantas daninhas competem com a cultura e reduzem o seu potencial produtivo, uma vez que sua presença foi capaz de interferir negativamente na produtividade em $33 \%$. No cultivo de inverno, o PAI estendeu-se até 12 dae, enquanto o PTPI prolongou-se até 34 dae (Figura 4b).

Em ambos os cultivos, o PAI ficou compreendido nos períodos iniciais, sendo de 16 e de 12 dae para cultivo no verão e no inverno, respectivamente (Figura 4a,b), coincidindo com os períodos de expressiva redução da massa da matéria seca (Figura 2a,b) e área foliar (Figura 3a,b) das plantas de girassol. Tal fato pode-se justificar pela correlação entre massa da matéria seca e de área foliar e a produtividade da cultura, conforme constatado por UnGARO et al. (2000) para massa da matéria seca e produtividade.

A temperatura mais baixa no início do cultivo de inverno pode ter influenciado o crescimento inicial do girassol e favorecido algumas espécies de plantas daninhas. Dessa forma, o girassol pode ter reduzido sua habilidade competitiva, o que resultou no PAI menor quando comparado ao cultivo de verão, quando as temperaturas foram mais elevadas e o PAI foi quatro dias maior.

\section{CONCLUSÃO}

A convivência do girassol com as plantas daninhas interfere negativamente na produtividade da cultura. A época de cultivo do girassol Helio 250 afetou os períodos de interferência das plantas daninhas na cultura. Para a produtividade de aquênios no verão, o período anterior à interferência foi de 16 dae da cultura, o período total de prevençáo à interferência foi de 39 dae e o período crítico de prevenção à interferência abrangeu 23 dias do ciclo da cultura. No inverno, o período anterior à interferência foi de 12 dae, o período total de prevenção à interferência estendeu-se até os 34 dae, resultando em um período crítico de prevençâo à interferência de 22 dias.

\section{REFERÊNCIAS}

ADEGAS, F.S.; OLIVEIRA, M.F.; VIEIRA, O.V.; PRETE, C.E.C.; GAZZIERO, D.L.P.; VOLL, E. Levantamento fitossociológico de plantas daninhas na cultura do girassol. Planta Daninha, v.28, p.705716, 2010. http://dx.doi.org/10.1590/S0100-83582010000400002

ALVES, G.S.; TARTAGLIA, F.L.; ROSA, J.C.; LIMA, P.C.; CARDOSO, G.D.; BELTRÁO, N.E.M. Períodos de interferência das plantas daninhas na cultura do girassol em Rondônia. Revista Brasileira de Engenharia Agrícola e Ambiental, v.17, p.275-282, 2013. http:// dx.doi.org/10.1590/S1415-43662013000300005

ANDRADE, J.A.; ABREU, F.G. Influência da temperatura e do teor de umidade do solo na área foliar e acumulação de matéria seca 
durante o estabelecimento da ervilha, do milho e do girassol. Revista de Ciências Agrárias, v.30, p.27-37, 2007.

BARNI, N.A.; BERLATO, M.A.; BERGAMASCHI, H.; RIBOLDI, J. Rendimento máximo do girassol com base na radiação solar e temperatura: II. Produção de fitomassa e rendimento de grãos. Pesquisa Agropecuária Gaúcha, v.1, p.201-216, 1995.

BRIGHENTI, A.M.; CASTRO, C.; OLIVEIRA JUNIOR, R.S.; SCAPIM, C.A.; VOLL, E.; GAZZIERO, D.L.P. Períodos de interferência de plantas daninhas na cultura do girassol. Planta Daninha, v.22, p.251-257, 2004. http://dx.doi.org/10.1590/S010083582004000200012

CASTIGLIONI, V.B.R.; BALLA, A.; CASTRO, C.; SILVEIRA, J.M. Fases de desenvolvimento da planta de girassol. Londrina: EmbrapaCNPSO, 1997. 24p. (Documentos, n.58).

CHUBB, W.O.; FRIESEN, G.H. Wild oat interference in sunflower. Canadian Journal Plant Science, v.65, p.219-222, 1985. http://dx.doi. org/10.4141/cjps85-031

ELEZOVIC, I.; DATTA, A.; VRBNICANIN, S.; GLAMOCLIJA, D.; SIMIC, M.; MALIDZA, G.; KNEZEVIC, S.Z. Yield and yield components of imidazolinone-resistant sunflower (Helianthus annuus L.) are influenced by pre-emergence herbicide and time of post-emergence weed removal. Field Crops Research, v.128, p.137-146, 2012. http:// dx.doi.org/10.1016/j.fcr.2011.12.020

EMPRESA BRASILEIRA DE PESQUISA AGROPECUÁRIA EMBRAPA. Centro Nacional de Pesquisa de Solos. Sistema Brasileiro de Classificaçáo de solos. 2.ed. Rio de Janeiro: Embrapa, 2006. 306p.

FLECK, N.G.; PINTO, J.J.O.; MENGARDA, I.P. Interferência de plantas daninhas na cultura do girassol. Competição no tempo. Pesquisa Agropecuária Brasileira, v.24, p.1139-1147, 1989.

FLECK, N.G; VIDAL, R.A. Efeitos de métodos físicos de controle de plantas daninhas sobre características agronômicas do girassol. Pesquisa Agropecuária Brasileira, v.28, p.1307-1318, 1993.

FURTADO, G.F.; SOUZA, J.R.M.; SOUZA JUNIOR, J.R.; LACERDA, R.R.A.; SOUZA, A.S. Períodos de interferência de plantas daninhas na cultura do girassol. Revista Verde de Agroecologia e Desenvolvimento Sustentável, v.7, p.12-17, 2012.

JOHNSON, B.J. Effect of weed competition on sunflowers. Weed Science, v.19, p.378-380, 1971.

KNEZEVIC, S.Z.; EVANS, S.P.; BLANKENSHIP, E.E.; ACKER, R.C.V.; LINDQUIST, J.L. Critical period for weed control: the concept and data analysis. Weed Science, v.50, p.773-786, 2002. http://dx.doi.org/10.1614/0043-1745(2002)050[0773:CPFWCT ]2.0.CO;2

KOZLOWSKI, L.A. Período crítico de interferência das plantas daninhas na cultura do milho baseado na fenologia da cultura. Planta Daninha, v.20, p.365-372, 2002. http://dx.doi.org/10.1590/S010083582002000300006
MONTOYA, J.C.; BERHONGARAY, G.; PÉREZ, A.; TITOLO, D.; TROIANI, H.; ROBERTO, Z.; RAMOS, L.; SAIBENE, Y.B. Relevamiento de malezas en cultivos de girasol de la província de La Pampa y zonas limítrofes. INTA, 2007. 30p. (Boletín de divulgación técnica).

PITELLI, R.A. Competição e controle de plantas daninhas em áreas agrícolas. Série Técnica IPEF, v.4, p.1-24, 1987.

PITELLI, R.A. Interferência de plantas daninhas em culturas agrícolas. Informe Agropecuário, v.11, p.16-27, 1985.

PORTO, W.S.; CARVALHO, C.G.P.; PINTO, R.J.B. Adaptabilidade e estabilidade como critérios para seleção de genótipos de girassol. Pesquisa Agropecuária Brasileira, v.42, p.491-499, 2007. http://dx.doi. org/10.1590/S0100-204X2007000400006

SILVA, J.I.C.; MARTINS, D.; PEREIRA, M.R.R.; RODRIGUESCOSTA, A.C.P.; COSTA, N. Determinação dos períodos de interferência de plantas daninhas na cultura do girassol. Planta Daninha, v.30, p.2736, 2012. http://dx.doi.org/10.1590/S0100-83582012000100004

SILVA, M.L.O.; FARIA, M.A.; MORAIS, A.R.; ANDRADE, G.P.; LIMA, E.M.C. Crescimento e produtividade do girassol cultivado na entressafra com diferentes lâminas de água. Revista Brasileira de Engenharia Agrícola e Ambiental, v.11, p.482-488, 2007. http:// dx.doi.org/10.1590/S1415-43662007000500006

SILVA, P.R.F.; RIZZARDI, M.A.; TREZZI, M.M.; ALMEIDA, M.L. Densidade e arranjo de plantas em girassol. Pesquisa Agropecuária Brasileira, v.30, p.797-810, 1995.

SOUSA, T.V.; ALKIMIM, E.R.; DAVID, A.M.S.S.; SÁ, J.R.; PEREIRA, G.A.; AMARO, H.T.R.; MOTA, W.F. Época de colheita e qualidade fisiológica de sementes de coentro produzidas no norte de Minas Gerais. Revista Brasileira de Plantas Medicinais, v.13, p.591597, 2011. http://dx.doi.org/10.1590/S1516-05722011000500015

SWANTON, C.J.; MAHONEY, K.J.; CHANDLER, K.; GULDEN, R.H. Integrated weed management: Knowledge-based weed management systems. Weed Science, v.56, p.168-172, 2008. http://dx.doi. org/10.1614/WS-07-126.1

THOMAZ, G.L.; ZAGONEL, J.; COLASANTE, L.O.; NOGUEIRA, R.R. Produçáo do girassol e teor de óleo nas sementes em diferentes épocas de semeadura no Centro-Sul do Paraná. Ciência Rural, v.42, p.203-208, 2012. http://dx.doi.org/10.1590/S010384782012005000010

UNGARO, M.R.G.; NOGUEIRA, S.S.S.; NAGAI, V. Parâmetros fisiológicos, produção de aquênios e fitomassa de girassol em diferentes épocas de cultivo. Bragantia, v.59, p.205-211, 2000. http://dx.doi. org/10.1590/S0006-87052000000200012

WANJARI, R.H.; YADURAJU, N.T.; AHUJA, K.N. Critical period of crop-weed competition in rainy-season sunflower (Helianthus annuus). Indian Journal of Agronomy, v.46, p.309-313, 2001. 